\title{
MUDANÇAS NO MULTILATERALISMO REGIONAL SUL-AMERICANO: PERSPECTIVAS DA SUBSTITUIÇÃO DA UNASUL PELO PROSUL
}

\author{
William Paiva Marques Júnior*
}

\section{RESUMO:}

A complexa realidade contemporânea nos países da América do Sul demonstra a existência de diversos fatores que desafiam a efetividade do PROSUL. A viabilidade de projetos integracionistas regionais deposita suas esperanças na ampliação da democracia, do constitucionalismo e da cidadania. Utiliza-se, como metodologia, de pesquisa do tipo bibliográfica por meio da análise de livros, artigos jurídicos, documentos internacionais, da legislação e da jurisprudência. A pesquisa é pura e de natureza qualitativa, com finalidade descritiva e exploratória.

PALAVRAS-CHAVES: mudanças; América do Sul; multilateralismo regional; UNASUL; PROSUL.

\section{CHANGES IN SOUTH AMERICAN REGIONAL MULTILATERALISM: PERSPECTIVES FOR UNASUR'S SUBSTITUTION BY PROSUR}

\begin{abstract}
:
The complex contemporary reality in the countries of South America demonstrates the existence of several factors that challenge the effectiveness of PROSUR. The feasibility of regional integrationist projects places its hopes in the expansion of democracy, constitutionalism and citizenship. It is used, as a methodology, bibliographic research through the analysis of books, legal articles, international documents, legislation and jurisprudence. The research is pure and qualitative, with descriptive and exploratory purpose.
\end{abstract}

KEYWORDS: changes; South America; regional multilateralism; UNASUR; PROSUR.

\section{Introdução}

Questiona-se o futuro da integração regional sul-americana principalmente quanto a sua sobrevivência em uma relação de legitimação na qual os cidadãos e os governos aparentemente apresentam-se em posições antagônicas, afinal, a existência de conflitos é ínsita ao espírito democrático.

\footnotetext{
* Doutor e Mestre em Direito Constitucional pela UFC. Professor Adjunto I do Departamento de Direito Privado da Faculdade de Direito da UFC de Direito Civil II (Direito das Obrigações) e Direito Civil V (Direito das Coisas). Coordenador da Graduação em Direito da UFC (2014 a 2017). Assessor do Reitor da UFC. Docente do Programa de Pós-Graduação em Direito da UFC das disciplinas de Metodologia do Ensino Jurídico e Direito das Relações Internacionais e Contemporaneidade. Foi Advogado Júnior da ECT (Empresa Brasileira de Correios e Telégrafos), de 2008 a 2011. E-mail: williamarques.jr@gmail.com.
} 
As relações internacionais na primeira década do Século XXI foram marcadas por acontecimentos de grande relevo, como a guerra ao terror, promovida principalmente pelos Estados Unidos, a ascensão econômica chinesa, não apenas no entorno asiático, mas também em escala mundial, a mudança nos termos de troca em favor dos países produtores de bens primários, a extraordinária dinâmica de crescimento dos anos de 2003 a 2007, a crise financeira sistêmica desde 2008 e a recuperação do crescimento econômico dos países em desenvolvimento. Esses fenômenos sinalizam modificações estruturais no sistema econômico e político internacional, configurando novas relações estatais e o fortalecimento de outros projetos integracionistas, dentre os quais avultam em importância o MERCOSUL e, mais recentemente o PROSUL, ambos na América do Sul.

Por sua relevância na economia, no território e na população, o Brasil se consolidou como uma grande liderança regional na América do Sul, especialmente a partir da década de 1990 quando do surgimento do MERCOSUL. Na esfera internacional, para além do plano sul-americano, o poder de influência brasileiro tem-se mostrado consideravelmente menor, principalmente a partir de uma nova inserção internacional da matriz da política diplomática brasileira, ora em formação. Aborda-seo PROSUL, como mais recente tentativa de integração regional sul-americana, compreendidos os dois movimentos em uma relação dialética e simbiôntica, pontuandose os contributos a partir da integração almejada pela UNASUL, recentemente.

Em março de 2019, foi realizada em Santiago/Chile, reunião de presidentes sul-americanos, ocasião em que se adotou a "Declaração Presidencial sobre a Renovação e o Fortalecimento da Integração da América do Sul". Por meio do documento referenciado, oito países (Argentina, Brasil, Chile, Colômbia, Equador, Guiana, Paraguai e Peru) indicaram sua vontade em estabelecer as bases para o lançamento do Foro para o Progresso da América do Sul (PROSUL). Conforme as linhas diplomáticas contemporâneas, a iniciativa se propõe a substituir, para esses países, o papel inicialmente conferido à UNASUL, no contexto de uma política diplomática brasileira contemporânea sem clareza, tampouco de rumos claros.

Utiliza-se, como metodologia, de pesquisa do tipo bibliográfica por meio da análise de livros, artigos jurídicos, documentos internacionais e da legislação. A pesquisa é pura e de natureza qualitativa, com finalidade descritiva e exploratória. 


\section{Reflexos da UNASUL no multilateralismo regional da América do Sul}

Não existe precedente na história da América do Sul de um bloco com objetivos tão amplos quanto a UNASUL. O fortalecimento das instituições internas é um mecanismo apto a tornar-se elemento propulsor da integração regional.

Sobre o processo de integração disposto no art. $4^{\circ}$-, parágrafo único da CF/88, averba José Souto Maior Borges (2005, pág. 183): não a mera integração econômica, mas a integração política, social e cultural da América Latina. Não um simples mercado comum, mas a integração de todos esses fatores econômicos e extraeconômicos no sentido de que transcendem, esses últimos, a órbita estrita da economia. A ideia de integração envolve a noção de totalidade. Sem a totalidade convergente dos princípios que regem essa integração, a comunidade não seria, a rigor, íntegra, nem seria possível se manifestar a integridade dos destinos da América Latina. O seu direito não seria um direito de integração. Com essa programação de integração comunitária, o constituinte de 1988 mostrou-se generoso, indo ao encontro das aspirações nacionais generalizadas, abrigadas e incorporadas pelo art. $4^{\circ}$ - nos seus diversos itens.

O alcance dos objetivos traçados no Tratado Constitutivo da UNASUL busca o aproveitamento e o aprimoramento das políticas integracionistas já entabuladas pela CAN e pelo MERCOSUL. Assim, a UNASUL já dispõe de um mercado comum; de projetos de cooperação de sede de infraestrutura: como a construção, ora em andamento, do corredor bioceânico (constituído de milhares de quiilômetros de rodovias que atravessarão a América do Sul no sentido leste-oeste), do Anel Energético SulAmericano (com o escopo de construção de uma rede de gasodutos na América do Sul), e do projeto Gás de Camisea (proposto para a extração de gás natural de diversas fontes da região); a livre circulação de pessoas; uma política monetária comum a cargo do Banco do Sul, com sede em Caracas, na Venezuela, com projeto para uma moeda única sul-americana.

No exame de Antonio José Ferreira Simões (2011, pág. 60), no inerente à infraestrutura, a UNASUL tem o desafio de modificar seu modelo tradicional de "desenvolvimento para fora"- ou seja, voltado exclusivamente para os centros dinâmicos da economia mundial- para complementá-lo com um modelo de "desenvolvimento para dentro", ou seja, destinado a explorar as possibilidades dentro da 
América do Sul. A internalização do dinamismo econômico passa pela criação da infraestrutura necessária-como as rodovias, ferrovias, pontes, ligações aéreas e marítimas, comunicações etc.

Como corolário do disposto no Art. $5^{\circ}$ - do Tratado Constitutivo da UNASUL, que trata do desenvolvimento da institucionalidade do Bloco, a UNASUL apresenta oito Conselhos Ministeriais: a) Energia; b) Saúde; c) Defesa; d) InfraEstrutura e Planejamento; e) Desenvolvimento Social; f) Problema Mundial das Drogas; g) Educação, Cultura, Ciência, Tecnologia e Inovação; h) Economia e Finanças. A UNASUL conta ainda com dois Grupos de Trabalho: a) Integração Financeira (agora subordinado ao Conselho de Economia e Finanças); e b) Solução de Controvérsias em Matéria de Investimentos, em cujo âmbito estuda-se a possibilidade de criar mecanismo de arbitragem, Centro de Assessoria Legal e código de conduta para membros de tribunais arbitrais.

Explicita André Panno Beirão (2010, pág. 47): a UNASUL nasceu como vontade de seus Estados-membros em criar um fórum intergovernamental que pudesse, com maior peso relativo, representar os interesses uníssonos da região, buscando, assim, uma identidade para com o cenário internacional. Suas ações decorrentes parecem, no entanto, mais voltadas ao público interno de seus membros constitutivos do que de projeção internacional.

A criação do Conselho Sul-Americano de Defesa (CDS) no âmbito da UNASUL, mais do que a intenção de fortalecer o Sistema Interamericano de Segurança (SIS), mediante a fundação de instâncias sub-regionais de apoio à atuação da Organização dos Estados Americanos (OEA), demonstra o propósito dos países sulamericanos, de inaugurarem uma experiência de regionalismo que constitua também uma instância própria de cooperação em segurança e defesa - sem a participação estadunidense - para tratar dos conflitos regionais, tradicionalmente submetidos ao imperialismo diplomático dos Estados Unidos.

É notória a fragmentação que sempre foi uma característica marcante da América do Sul. A realidade contemporânea revela que as ondas da globalização atraem em um processo simultâneo os países que demonstram bom desempenho, excluindo os demais, contribuindo, dessa maneira, não apenas para a perpetuação do histórico de 
fragmentação, mas também ensejando ressentimento mediante o estabelecimento de uma arena de vencedores e perdedores.

De acordo com Leandro Rocha de Araújo (2008, pág. 130), os principais obstáculos para os esforços de integração na América Latina nos últimos 30 anos estão relacionados a fatores como a falta de um objetivo claramente afirmado nas agendas nacionais e inserido na respectiva política econômica dos Estados, relacionado à integração. Além disso, alguns setores nacionais não se sentem atraídos pela ideia de integração regional, uma vez que se beneficiam ou se beneficiavam de pesados auxílios estatais, protecionismo oficial e reserva de mercado.

Ao reverso da América do Sul, nas últimas décadas, a Europa passou por um processo de maior convergência, tanto que os países do Continente se tornam cada vez mais similares em termos de desenvolvimento político, social, econômico e qualidade institucional. Na análise da heterogeneidade da situação sul-americana, revelam-se tanto elementos de mudança como de continuidade, que, em diversas oportunidades, apontam rumo às divergências: alguns países consolidam definitivamente os seus regimes democráticos (na tentativa de aprimorar e estabelecer um modelo cada vez mais participativo) o que reverbera num veloz desenvolvimento social e econômico, ao passo que outros ingressam numa fase de desorganização institucional, pobreza e violência endêmicas.

Isso decorre do fato de que alguns dos países sul-americanos denotam indicadores de desenvolvimento humano, mais próximos dos patamares das nações menos desenvolvidas do Globo do que dos níveis regionais. Em alguns casos, a pobreza é acompanhada de instabilidade política, e mesmo de violência, com violações aos direitos humanos, dada a incapacidade estatal na tarefa primária de garantia da ordem pública. Um exemplo exitoso de superação é a Colômbia, que até recentemente poderia ser incluída neste grupo de países, não por seu razoável desempenho econômico, mas por sua inabilidade político-institucional no controlar do território nacional e na garantia da autoridade do Estado de Direito. Esta realidade, no entanto, melhorou visivelmente nos últimos anos, notadamente durante o governo do ex-Presidente Álvaro Uribe (20022010) que minimizou o poder paraestatal desenvolvido pelas FARC (Forças Armadas Revolucionárias da Colômbia). 
De acordo com Graciela de Conti Pagliari (2009, pág. 164), as FARC, consideradas como um grupo terrorista pelos EUA e pela Colômbia, atuam como grupo colombiano insurgente no País desde a década de 1960. Nos anos de 1980, com a transferência de grandes porções de plantação de coca do Peru e da Bolívia para a Colômbia, as FARC passaram a financiar suas atividades extremistas com os recursos provindos do tráfico de drogas.

Como resultado da instabilidade crônica e dos altos índices de pobreza e desigualdade, é difícil que alguns países atinjam um nível de desenvolvimento social sustentável, apesar da possibilidade de, eventualmente, alcançarem altas taxas de crescimento econômico. O caso argentino, por exemplo, está eivado de anacronismos: o seu alto potencial e a sua história favorável não foram suficientes para evitar o tipo de administração incompetente que conduziu um contexto de extrema crise política, social e econômica agravada no segundo governo de Cristina Kirchner. O Uruguai, por seu turno, é um caso excepcional, uma vez que o fraco desempenho econômico não afetou o funcionamento das instituições políticas e dos níveis de desenvolvimento humano.

Conforme esposado por Luiz Felipe Viel Moreira, Marcela Cristina Quinteros e André Luiz Reis da Silva (2010, págs. 357), tanto a Guiana quanto o Suriname procuram uma aproximação maior com os países sul-americanos, principalmente após a Cúpula de Brasília, em 2000, que lançou o projeto de integração regional. Assim, a Guiana e o Suriname, de tradição cultural e movimentação histórica diferenciadas do restante da América do Sul, constituem uma fronteira nova a ser tratada no contexto da integração do subcontinente.

Como países bem-sucedidos, encontram-se o Brasil e o Chile, exprimindo modelos distintos de desenvolvimento e estratégia no projeto integracionista global: o Brasil optou pela industrialização direcionada para o mercado externo, ao passo que o Chile escolheu uma estratégia de liberalização unilateral e de inserção global baseada nos múltiplos tratados bilaterais. Espera-se que esses países mantenham as suas estratégias que, em ritmos diferenciados, têm permitido o crescimento econômico e social (maior no Chile e menor no caso brasileiro), a consolidação da democracia e o consequente aumento da qualidade de vida dos cidadãos.

Os países da América do Sul possuem em comum diversos fatores geográficos, econômicos, políticos, históricos, sociais e culturais que tornam sua 
integração uma realidade plausível. As assimetrias entre os países sul-americanos não são capazes de impedir a necessidade de aprofundamento da integração sul-americana tornando-se genuíno imperativo ante o esmagador processo de globalização em curso, que reserva aos países em desenvolvimento, por meio de uma inserção secundária no plano das relações internacionais. Sem vontade política interna, não há integração.

A UNASUL não se mostra instituição que concorre com o MERCOSUL. São instituições convergentes, que visam às atividades harmônicas, coordenadas e complementares para a superação das inúmeras assimetrias e dos entraves que ainda impedem o desempenho exitoso da efetiva integração sul-americana. Por seu turno, desde o seu nascedouro, o PROSUL mostra-se como projeto antitético e concorrente no tocante à UNASUL.

Neste jaez assevera Antonio José Ferreira Simões (2011, pág. 46), a noção de que o estabelecimento político da integração ocorre em círculos concêntricos, haja vista que longe de representarem iniciativas excludentes, podem ser consideradas, ao contrário, elaborações diplomáticas que possuem distintos níveis de ambição, mas que apontam na mesma direção de uma região mais unida e integrada. Na visão do autor, para o Brasil, o MERCOSUL continuará sendo o núcleo duro da integração.

Atualmente observa-se que a América do Sul (apesar de suas assimetrias), campeia como modelo predominantemente democrático no Hemisfério Sul, fator considerado fundamental para o êxito do processo integracionista.

Conforme o diagnóstico de José Souto Maior Borges (2005, pág. 185), o MERCOSUL ainda está muito longe de atingir o objetivo da integração comunitária dos países da América Latina, entendida como uma estrutura política, social, econômica e cultural- e não apenas econômica. Esse distanciamento é facilmente perceptível, não apenas porque só alguns países da América do Sul (Brasil, Argentina, Uruguai e Paraguai) o integram, mas também porque ele significa pouco mais de um bloco econômico interestatal.

Em 08 de dezembro de 2004, foi estabelecida a Comunidade Sul-Americana de Nações, com a adesão imediata dos doze países da América do Sul, mediante a assinatura da Declaração de Cuzco. Na instituição da CASA, reconheceu-se a convergência dos interesses políticos, econômicos, sociais, culturais e de segurança, como um fator 
potencial de fortalecimento e desenvolvimento das capacidades internas para a melhor inserção internacional dos países sul-americanos.

Durante a realização da I Cúpula Energética Sul-Americana realizada na Ilha de Margarita (Venezuela), em 2007, o bloco CASA passou a denominar-se UNASUL (União de Nações Sul-Americanas).

A criação da União de Nações Sul-Americanas - UNASUL composta pelos 12 (doze) países da América do Sul, em 2008, e da recente Comunidade dos Estados Latino-Americanos e Caribenhos (CELAC), esta última com origem na "Declaração da Cúpula da Unidade", adotada pelos Chefes de Estado e de Governo da América Latina e do Caribe durante reunião de Cúpula realizada na Riviera Maya, México, em fevereiro de 2010, mais do que uma repetição de esforços de blocos regionais já existentes, representa uma etapa da integração que pode ser denominada de autêntica, primeiramente porque supera o modelo de integração econômica que tem como fórmula a criação de uma zona de livre comércio, objetivando alcançar um mercado comum ou uma união monetária e econômica, a exemplo da União Europeia. Com efeito, os propósitos da UNASUL e da CELAC são mais ambiciosos porque visam a objetivos mais complexos e que consideram a superação das assimetrias e vulnerabilidades que afastam os países do caminho da integração. Estabelecer mecanismos que transpõem o mercado é fundamental para superar definitivamente o ideário integracionista pautado na liberalização do comércio que teve expressão significativa no projeto da Área de Livre Comércio das Américas - ALCA.

A originalidade do processo de integração da UNASUL encontra-se materializada na constatação de que, diferentemente de outros blocos que ordinariamente iniciam as tratativas integracionistas por meio de acordos econômicos, para só depois ultrapassar as esferas institucionais e políticas, a UNASUL demonstra percorrer o caminho inverso, uma vez que sua gênese se atrela às questões políticas e à elaboração de acordos em diversas áreas, incluindo a tradicional agenda econômica dos processos integracionistas.

Para Antonio José Ferreira Simões (2011, pág. 62), a UNASUL tem outras dimensões centrais. A econômico-comercial é fundamental, porém não pode ser posta na frente das demais. O objetivo a ser alcançado é fazer convergir os processos de integração comercial que, em separado, buscaram o MERCOSUL, a Comunidade 
Andina, o Chile, o Suriname e a Guiana. Observe-se: a UNASUL não estabeleceu metas quanto ao alcance do livre comércio até uma data determinada. Sua abordagem mais pragmática e flexível visa a fazer com que os avanços no sentido da abertura e integração econômica se façam à medida que possam ser aceitos pelos setores econômicos dos vários países, de forma que sejam sustentados no longo prazo. Também é necessário frisar a importância da dimensão social da UNASUL, cuja velocidade pode até mesmo superar a da área comercial.

A realidade contemporânea demonstra que a América do Sul continua a aparecer como um continente de promessas não cumpridas. Malgrado o seu enorme potencial geográfico proporcionado pela abundância de recursos naturais (incluindo a riqueza em fontes energéticas) e o capital humano expresso em uma alta possibilidade de fornecimento de mão de obra, suas sociedades continuam imersas em indicadores de desenvolvimento social e econômicos relativamente baixos.

Conforme aduz Antonio José Ferreira Simões (2011, pág. 57), a UNASUL é, na essência, o arcabouço sob o qual se procura articular as relações de aproximação e integração entre os países da América do Sul nos mais diversos campos. A integração sul-americana dá-se em torno do que podem ser chamadas de áreas estruturantes. $\mathrm{O}$ Tratado Constitutivo da UNASUL lista os campos da concertação política, da energia, da infraestrutura, do comércio, do meio ambiente, das políticas sociais. Deixa claro o fato de que a relação não é exaustiva e está aberta a oportunidades eventuais de integração em outros domínios.

Observam Luiz Felipe Viel Moreira, Marcela Cristina Quinteros e André Luiz Reis da Silva (2010, págs. 379) que, além do MERCOSUL e da ALBA (“Alternativa Bolivariana das Américas", articulado por Venezuela e Cuba, com participação de diversos países), a resposta veio com o projeto de integração da América do Sul, lançado em 2000, na Primeira Cúpula de Presidentes Sul-Americanos. Essa proposta avançou e, desde 2007, está sendo construída a União das Nações SulAmericanas (UNASUL). Com o fracasso da ALCA, evidenciado na Cúpula de Mar del Plata, em 2005, os Estados Unidos intensificaram a estratégia de minar o projeto de integração latino-americana, oferecendo tratados de livre-comércio bilaterais. Na América do Sul, esta estratégia seduziu alguns países, como Chile, Colômbia e Peru. 
Esses países, no entanto, também participam do processo de integração da América do Sul.

Representativa da influência norte-americana na América do Sul foi a política desenvolvida pelo ex-presidente colombiano Álvaro Uribe que se encontrava em sintonia com a agenda republicana do então Presidente George Bush, centrada nas agendas do narcotráfico, do livre-comércio e do combate ao terrorismo.

Para André Panno Beirão (2010, pág.42), os Estados Unidos têm buscado com as relações com a Colômbia e a presença de bases militares em países da região, bem como permitindo o rearmamento chileno, uma sutil, embora concreta, ação de contenção preventiva a uma futura expansão econômica, tecnológica e até militar do único ator sub-regional com potencial de desafiar a liderança hemisférica dos Estados Unidos no subcontinente: o Brasil, justamente o país que se mostra como o aliado estratégico e que possui uma vocação pacífica em suas relações internacionais.

Os aspectos históricos comuns dos povos autóctones desta região plural foram resultado de lutas essenciais na conquista de identidade única, hoje representada no paradigma da cidadania regional.

As instituições ocupam um lugar muito importante nos processos de integração da América do Sul. As primeiras experiências integrativas encontraram, como um de seus obstáculos para a sua efetividade, a ausência de uma relação dialógica com as instituições políticas e com os anseios democráticos, o que implicava descrédito e consequente fracasso das metas inicialmente traçadas (art. 18 do Tratado Constitutivo da UNASUL).

A democratização das relações institucionais entre os países da UNASUL funda-se em critérios dialógicos como norteadores do processo político regional, consoante normatizado pelo Art. 14 do Tratado Constitutivo.

Na visão de Antonio José Ferreira Simões (2011, pág. 64), o trabalho diplomático na área de integração é precisamente tratar de cada uma das dificuldades que são naturais- e encontrar saídas para superá-las. No processo de construção da integração da América do Sul, deve prevalecer um elevado sentido de pragmatismo. Embora se atribua prioridade às dimensões estruturantes da integração- como a energia, a infraestrutura e a política- não há predefinições que engessem as oportunidades de avanços, nem metas artificiais. 
A UNASUL, tem uma proposta de integração que ultrapassa o viés econômico e alcança, com muito maior força, as esferas de defesa, energética, cultural, social, ambiental e democrática. Percebe-se, da análise do Tratado Constitutivo do Bloco, que a prioridade na promoção da participação cidadã é bastante evidente em vários momentos.

Analisando-se a integração sul-americana sob a óptica diplomática brasileira, observam-se os esforços envidados na criação da UNASUL. Para tal desiderato, contribuíram diversos fatores, dentre os quais avulta em importância a dificuldade na expansão e fortalecimento do MERCOSUL, considerando-se a rigidez de sua natureza, bem como da perspectiva expansionista do processo integracionista sulamericano para áreas não albergadas no MERCOSUL. O elemento "flexibilidade", nos projetos de integração, pode ser entendido como elemento que dificulta a formação de uma área de livre-comércio ante a ausência de coerência interna entre os países. Por outro lado, colabora para a coesão do continente em questões consensuais, como a expansão da infraestrutura logística e a necessidade premente de integração energética, na superação de défices que se prolongam há décadas.

Consoante a análise de Eduardo dos Santos (2010, pág. 21), a continuidade e a ampliação do projeto sul-americano de integração, consubstanciado na UNASUL, refletem o seu fundamento essencialmente geográfico no que diz respeito ao reforço das obras de integração física e energética. Apesar de que seu conteúdo auferiu uma dimensão política mais abrangente, sobretudo com o maior relevo que se dá à defesa da estabilidade democrática e à solução de conflitos, é um processo respeitante a países vizinhos, que compartilham o mesmo espaço e que hoje, cada vez, mais estão unidos por pontes, estradas, ferrovias, hidrelétricas, gasodutos e linhas de transmissão.

Desde 2017, quando o ex-presidente colombiano Ernesto Samper concluiu seu período à frente do organismo, a UNASUL está sem secretário-geral por força da ausência de consenso entre os seus membros, bem como sem fontes de custeio para a manutenção de suas atividades.

\section{A complexa realidade contemporânea na América do Sul como desafio imposto à efetividade do PROSUL}

A prosperidade da América do Sul, em uma realidade contemporânea, depende sobretudo do resgate da altivez no plano da política externa. Necessita, 
principalmente do fortalecimento de valores como a cidadania inclusiva, a dignidade da pessoa humana e a democracia. Nessa ordem de ideias, os acordos de integração regional sul-americana devem servir de mecanismos de propulsão para o desenvolvimento social, econômico e político regional.

O recém-criado Fórum para o Progresso e Desenvolvimento da América do Sul (PROSUL) representa um processo de integração mais pragmático e orientado para resultados econômicos. A partir da criação do PROSUL o MERCOSUL assume um papel mais voltado para o livre comércio. Com a nova função do MERCOSUL em 2019 foram priorizadas relações do Bloco com a União Europeia, com a Associação Europeia de Livre Comércio e com o Canadá.

O recente acordo do MERCOSUL com a União Europeia fez parte de um processo de intensificação da agenda do projeto em negociações externas, que também incluiu rodadas com a Associação Europeia de Livre Comércio, o Canadá, a Coreia, Singapura, formando um amplo programa de negociações externas que se encontra articulado com a política diplomática brasileira.

No plano prospectivo, o ideal é que o Brasil necessita de uma política externa a mais ampla possível e talvez o PROSUL não atenda a essa expectativa. No momento, não se verifica uma diretriz clara para a política diplomática brasileira. Um dos principais desafios da atual gestão do Itamaraty é encontrar uma clareza nos rumos externos.

Parece clara a diretriz da política diplomática brasileira contemporânea no sentido da busca de uma relação privilegiada com os Estados Unidos, mas esse alinhamento ao invés de beneficiar, pode vir a atrapalhar a integração regional sulamericana, menoscabando o papel do Brasil como potência regional, ao passo que nos governos brasileiros após a redemocratização verificava-se uma a busca de autonomia por participação. Da redemocratização até o final de 2018, a política diplomática nacional não queria retornar àqueles períodos do passado em que o Brasil se via como um aliado dos Estados Unidos.

No plano das relações internacionais, para além da América do Sul, o poder de influência brasileiro é consideravelmente menor. Sem dispor de poderio econômico, tampouco militar, a tradição diplomática brasileira se baseia no soft power, principalmente enfatizando a participação em instituições multilaterais. No final da 
década de 1980, com o processo de redemocratização, o Brasil também ganhou relevância por sua defesa em temas como os direitos humanos.

Criado em um contexto de caos político, social, econômico e humanitário na Venezuela, o PROSUL não expressa de forma direta estratégias claras para os problemas dos refugiados venezuelanos, fato é que o país não se encontra presente no novo projeto integracionista. No plano prospectivo, observa-se que o PROSUL surge com o nítido objetivo de substituir a UNASUL. Nesse diapasão, o surgimento do PROSUL também é uma forma de países da região isolarem a Venezuela, governada por Nicolás Maduro. O aludido isolamento se dá porque Brasil, Argentina e Colômbia estão entre os países que não reconhecem a legitimidade de Maduro e consideram o líder oposicionista Juan Guaidó como presidente interino da Venezuela, desse modo, a disputa pela legitimidade presidencial na Venezuela reverbera no plano da interação regional sul-americana.

Como um dos problemas contemporâneos mais contundentes na América Latina apresenta-se o caso da Venezuela. Ao longo da última meia década, o Presidente Nicolás Maduro perseguiu e prendeu arbitrariamente opositores, anulou o Parlamento que apresentava-se como contraponto político, fechou os meios de comunicação não alinhados ao seu governo e militarizou o país, inclusive com milícias de apoiadores armados que atuam na intimidação de cidadãos contrários ao regime liberticida.

Todo esse caos gerou uma diáspora de milhões de venezuelanos. Em maio de 2018, o Presidente foi reeleito em sufrágio realizado sob o domínio do líder plenipotenciário, revelando um caso extremo de hiperpresidencialismo e perpetuação no poder com um alto custo para a democracia na região.

São tantas as crises provocadas na recente história da democracia latinoamericana que o discurso proferido pelo escritor colombiano Gabriel García Márquez (2010, online) ao receber o Prêmio Nobel de Literatura, em 1982 ainda faz sentido: “...a independência do domínio espanhol não nos colocou a salvo da demência." dos governantes de plantão.

A iniciativa do PROSUL se deu pela atuação dos atuais presentes do Chile (Sebastián Piñera) e da Colômbia (Iván Duque) garantindo papel protagonista a ambos países na construção do PROSUL. Bolívia, Suriname e Uruguai, somados à Venezuela e à Guiana, são os únicos membros ativos restantes na UNASUL, após a saída de todos os 
demais países, com a criação do PROSUL, incluindo o Equador, país sede daquele Bloco. Com a retirada da UNASUL, o Equador requereu a devolução da então sede, em Quito.

A proposta de criação do Foro para o Progresso da América do Sul (PROSUL), projeta uma articulação que reflita a atual agenda e aspirações dos governos sul-americanos, em contraponto frontal à UNASUL. No aspecto prospectivo prevê a criação de um mecanismo de coordenação para políticas públicas em defesa da democracia, independência de poderes, economias de mercado e agenda social com sustentabilidade, porém em uma estrutura de maior flexibilidade em relação a custos e mecanismos decisórios, além de não prever uma sede própria, diferentemente da UNASUL, cuja sede se encontra em Quito/Equador. Considerando tratar-se o PROSUL de um projeto bastante recente, não se pode antever tal grau de diferenciação na prática no tocante à UNASUL, tendo em vista que as ideias divulgadas sugerem uma natureza de cooperação similar à da organização sul-americana pregressa, embora com especificidades que merecem ser melhor explicitadas e analisadas.

Conforme aduzem Mônica Salomón e Letícia Pinheiro (2013, p. 53), uma lacuna a ser analisada na política diplomática brasileira refere-se aos estudos centrados no líder. Essa ausência chama atenção não apenas pela natureza do presidencialismo imperial brasileiro, o que por si só já seria razão suficiente para avaliar as características particulares do mandatário na política externa.

A Declaração Presidencial sobre a Renovação e o Fortalecimento da Integração da América do Sul ocorreu em Santiago/Chile, em 22 de março de 2019 (ITAMARATY, 2020, online), da qual participaram os Chefes de Estado da República Argentina, da República Federativa do Brasil, da República do Chile, da República da Colômbia, da República do Equador, da República Cooperativa da Guiana, da República do Paraguai e da República do Peru serviu como base para a construção do PROSUL.

Em seu Preâmbulo, a Declaração Presidencial sobre a Renovação e o Fortalecimento da Integração da América do Sul reafirmou que o processo de construção de espaço de coordenação, cooperação e integração regional deve respeitar a integridade territorial dos Estados, o direito e a segurança internacionais, além de estar comprometido com a preservação da América do Sul como Zona de Paz, bem como reconheceu as contribuições de processos anteriores de integração sul-americana, assim 
como a necessidade de preservar o seu acervo, no marco de novo espaço de integração mais eficiente, pragmático e de estrutura simples, que permita consolidar seus êxitos e promover a evolução sem duplicação de esforços, em direção a uma região mais integrada (ITAMARATY, 2020, online), mesmo que contextualmente tenha surgido do confronto ideológico com a UNASUL.

As áreas estratégicas de atuação do PROSUL encontram-se previstas nos números 04 e 05 da Declaração Presidencial sobre a Renovação e o Fortalecimento da Integração da América do Sul, quais sejam: “4. Que este espaço abordará de maneira flexível e com caráter prioritário temas de integração em matéria de infraestrutura, energia, saúde, defesa, segurança e combate ao crime, prevenção de e resposta a desastres naturais.”, bem como: "5. Que os requisitos essenciais para participar deste espaço serão a plena vigência da democracia e das respectivas ordens constitucionais, o respeito ao princípio de separação dos poderes do estado, e a promoção, proteção, respeito e garantia dos direitos humanos e das liberdades fundamentais, assim como a soberania e a integridade territorial dos estados, em respeito ao direito internacional."

O Chile encontra-se no exercício da Presidência Pro Tempore (PPT) do PROSUL, devendo ser sucedido pelo Paraguai.

Com a criação do PROSUL, em abril de 2018, os governos de Brasil, Argentina, Chile, Colômbia, Paraguai e Peru decidiram de forma conjunta suspender a sua participação da UNASUL em função da prolongada crise no organismo, considerando ainda a criação no mês anterior do PROSUL.

Em abril de 2019, o governo brasileiro denunciou o Tratado Constitutivo da União de Nações Sul-Americanas (UNASUL), formalizando sua saída da organização. A decisão foi comunicada oficialmente ao governo do Equador, país depositário do acordo, e surtirá efeitos transcorridos seis meses a contar de então.

Decerto o constructo democrático e garantista nos países acometidos pelos movimentos sociais libertários, na América do Sul, amoldam-se à constatação de Amartya Sem (2011, pág. 386) consoante a qual: a liberdade democrática pode certamente ser usada para promover a justiça social e favorecer uma política melhor e mais justa. O processo, entretanto, não é automático e exige um ativismo por parte dos cidadãos politicamente engajados. 
Como diferenças visíveis, o PROSUL não deve ter um tratado e não será um organismo, como a UNASUL. Outra diferença objetiva se dá quanto aos países membros: enquanto participaram da UNASUL os 12 países sul-americanos, no PROSUL 4 deles ficaram de fora até o momento: Uruguai, Bolívia, Suriname e Venezuela. No aspecto subjetivo-ideológico, outra diferença é verificada pela seguinte constatação: enquanto as lideranças que fundaram a UNASUL tinham um perfil mais voltado à esquerda (o que não indica necessariamente que o bloco seja uma organização de esquerda), as do PROSUL são mais voltadas à direita (da mesma forma, não necessariamente o organismo é um fórum de direita) até porque, conforme vaticina Norberto Bobbio (2011, pág. 123), a distinção entre esquerda e direita refere-se ao diverso juízo positivo ou negativo sobre o ideal de igualdade, que deriva em última instância da diferença de percepção e de avaliação daquilo que torna os homens iguais ou desiguais, coloca-se em nível tão elevado de abstração que serve no máximo para distinguir dois tipos ideais.

No diagnóstico de Rubens Ricupero (2017, págs. 738 e 739), a diplomacia em geral fez sua parte e até então não se saiu mal em comparação a alguns outros setores. Chegou-se, porém, ao ponto extremo em que não mais é possível que um setor possa continuar a construir, se outros elementos mais poderosos, como o sistema político, comprazem-se em demolir. A partir de agora, mais ainda que no passado, a construção do Brasil terá que ser integral, e a contribuição da diplomacia na edificação dependerá da regeneração do todo.

A democracia pluralista não se coaduna com a ideologia da unanimidade. Seu maior desiderato é a promoção de uma institucionalização da divergência, ou seja, a permissão que representantes dos diferentes interesses gozem de liberdade para defender institucionalmente seus interesses, desde que estes se relacionem com os meios legais e participativos. Essa é a recomendação ideal para o êxito do projeto integracionista da América do Sul.

Para Gregorio Robles (1997, p. 153), se o pluralismo originalmente exigia a convivência no âmbito da democracia formal, hoje exige o desenvolvimento de uma democracia material (substantiva), estabelecida portanto não só em liberdades 'vazias' , mas também em critérios de política positiva que, do ponto de vista ético, não pode 
encontrar um assento na ideia individualista, mas na ideia da solidariedade e da responsabilidade.

Atualmente observa-se que a América do Sul (apesar de suas assimetrias), campeia como modelo predominantemente democrático no Hemisfério Sul, fator considerado fundamental para o êxito do processo integracionista. Após o lançamento e formalização de saída da UNASUL, as instâncias diplomáticas dos países do PROSUL, notadamente da diplomacia brasileira, agora devem concentrar esforços em grupos de trabalho para elaborar as bases para a criação da comunidade comum que aperfeiçoe e aprofunde as bases estabelecidas pelo MERCOSUL.

A análise histórica denota que a América do Sul é campo fértil para diversas iniciativas de multilateralismo. Os benefícios de décadas de esforços das políticas diplomáticas em mecanismos como ALALC, ALADI, MERCOSUL, Aliança do Pacífico, UNASUL e, mais recentemente, o PROSUL não podem ser olvidados: a região tem um histórico de baixo envolvimento em conflitos internacionais, é livre de armas nucleares e conseguiu superar muitas de suas principais rivalidades geopolíticas. No campo das relações internacionais bilaterais, os países sul-americanos têm logrado desenvolver amplas agendas, especialmente em matéria comercial.

Para Paulo Paulo Estivallet de Mesquita (2018, págs. 33 e 34), no contexto de otimismo em relação à mudança dos eixos globais de poder, os países latino-americanos lançaram uma série de iniciativas de integração regional, com diferentes escopos, entre as quais se destacam o MERCOSUL, a UNASUL e a CELAC. Construídos sob uma base econômica ou no sentimento de solidariedade e identidade latino-americana, esses mecanismos inevitavelmente sentem as pressões decorrentes das mudanças recentes. Hoje, para empregar uma expressão utilizada por Celso Lafer para descrever o cenário pós-Guerra Fria, vive-se um momento de explosão de particularismos na América Latina. É natural que, pelo menos em uma primeira reação, países se voltem para dentro diante do encerramento de um ciclo positivo e da necessidade de avaliar a melhor forma de mudar ou se adaptar à nova conjuntura. Contudo, esse processo gera efeitos inevitáveis nos processos de integração existentes.

Conforme destacado por Paulo Paulo Estivallet de Mesquita (2018, pág. 35), a UNASUL foi criada a partir da constatação da conveniência da atuação conjunta e da formulação de políticas comuns - ou pelo menos coerentes - em diversas áreas na 
medida em que os países sul-americanos se aproximam mais. Em temas como o combate à malária e integração da infraestrutura, fica evidente a necessidade de coordenação entre os governos da região. No entanto, houve determinado momento em que se presumiu uma coincidência de visões de mundo e objetivos que, na verdade, não existe. Nesse contexto, a UNASUL passa atualmente por dificuldades. Mesmo em casos em que exista interesse claro na convergência, o organismo não logrou obter resultados práticos.

No plano prospectivo, observam-se, entretanto, enormes desafios comuns aos países da região: a defesa inquebrantável da democracia, o desenvolvimento econômico, o combate à criminalidade, o reforço do Estado de Direito, a redução das desigualdades sociais, a proteção ao meio ambiente, dentre outros. A cada novo ciclo político pelo qual a região passa, o equacionamento desses desafios recebe diferentes visões. Quais as estratégias diplomáticas que se pode vislumbrar para a região nos próximos anos? Qual o papel da diplomacia brasileira para o processo de integração regional?

No diagnóstico da atual política diplomática brasileira, Renata Moraes Simões (2019, p. 1-19) ressalta que, com um forte discurso de ruptura, em 2019 é empossado o presidente Jair Bolsonaro. No intuito de dar continuidade ao que se chamou "desideologização" da política externa brasileira, Bolsonaro coloca à frente do MRE o diplomata Ernesto Araújo. Desde sua posse como ministro, Araújo verbaliza um denso questionamento às tradicionais ideias de multilateralismo e universalismo que por anos foram associadas à práxis do Itamaraty. Torna-se cada vez mais evidente os traços de ruptura que a gestão atual pretende imprimir nas relações exteriores do Brasil contrapondo-se à continuidade mantida desde o fim dos anos 1990. As transformações ocorrem na expectativa de demarcar uma via inovadora de atuação ao refutar o legado dos governos anteriores, bem como desconstruir seus vestígios. As relações exteriores brasileiras até o momento são demarcadas pela busca do alinhamento personalista ao presidente Donald Trump e da entrada brasileira na OCDE, que representam, na visão de Araújo, uma reparação histórica ao fato de que por décadas a política externa brasileira foi impregnada por uma ideologia antiamericanista e terceiro-mundista. No que condiz com o entorno regional do Brasil, a priorização dada ao eixo estadunidense coloca a América do Sul em uma posição de desprestígio na diplomacia brasileira. 
Conforme observa Renata Moraes Simões (2019, p. 1-19), a grande questão parece ser a troca de blocos regionais em detrimento da mudança de governo nos países. $\mathrm{Na}$ retórica, essa perspectiva se liga a um discurso recente acerca da flexibilização dos organismos internacionais. Na prática, quer dizer que novos governos chegam ao poder e apontam que as dinâmicas regionais estabelecidas em outros governos são engessadas e enviesadas. Logo existe a necessidade de se criar outro bloco e consequentemente inicia-se um processo de overlapping de regionalismos.

Ainda que não esteja muito bem delineada, em geral, a postura assumida pela política externa brasileira no governo Bolsonaro demonstra a intencionalidade de ruptura com os governos anteriores, em uma tentativa de esvaziamento e invalidação de seus legados, como ocorreu com a UNASUL, implicando em uma sobreposição de projetos integracionistas que não conseguem atingir suas finalidades institucionais.

Em março de 2020, os Chefes de Estado e Altos Representantes da República Federativa do Brasil, da República do Chile, da República da Colômbia, da República do Equador, da República do Paraguai e da República do Peru, bem como do Estado Plurinacional da Bolívia, em sua qualidade de estado observador, participaram de uma videoconferência presidida pelo chile, na qualidade de presidente pro tempore do PROSUL que resultou em declaração presidencial do bloco sobre ações conjuntas para enfrentar a pandemia do Coronavírus, (Covid-19), estabelecendo como uma de suas prioridades adotar critérios para a tomada de decisões no gerenciamento da emergência causada pelo Coronavírus, compartilhando diagnósticos confiáveis e informações epidemiológicas sobre o quadro pandêmico (ITAMARATY, 2020, online).

Observa-se que a Argentina não participou da reunião referenciada. Portanto abrem-se alguns questionamentos: (1) o PROSUL, com um perfil mais flexível e menos institucionalizado, será capaz de levar adiante o ainda recente processo de cooperação, integração e regionalismo na América do Sul? (2) Partindo-se da premissa que a Argentina, fundamental para a construção do bloco, passa por um processo de mutação da política diplomática com a substituição de Mauricio Macri por Alberto Fernández, seria possível esperar que o Brasil buscasse uma posição de destaque na consolidação do novo bloco? Questionamentos como esses deixam a posição brasileira na região incerta e ameaçam a estabilidade de um relacionamento ainda recente em que falta $o$ 
tradicional diálogo na relação Brasil-Argentina, dois dos mais importantes países do bloco.

Inegável que o Brasil ostenta papel relevante na cooperação necessária à efetividade do PROSUL, devendo fomentar mecanismos de coordenação com a organização, de modo a facilitar a cooperação sul-americana na construção de novos horizontes para o multilateralismo regional. Portanto, a defesa inquebrantável da democracia é fundamental para o êxito do processo integracionista regional sulamericano devendo haver o enfrentamento dos problemas regionais pelo PROSUL.

Desta forma, coaduna-se com Darcy Ribeiro (2006, pág. 158), ao vaticinar o fato de que o destino é o Brasil se unificar com todos os latino-americanos pela sua oposição comum ao mesmo antagonista, que é a América anglo-saxônica, para se fundar, tal como ocorre na comunidade europeia, a Nação Latino-Americana sonhada por Bolívar. Hoje, são 500 milhões, amanhã será 1 bilhão; vale dizer, um contingente humano com magnitude suficiente para encarnar a latinidade em face dos blocos chineses, eslavos, árabes e neobritânicos na humanidade futura. São povos novos ainda na luta para se fazer como um gênero humano novo que nunca existiu, tarefa muito difícil e penosa, mas também muito mais bela e desafiante.

\section{Considerações Finais}

Para um futuro emancipatório e inclusivo para a efetividade do PROSUL propõe-se mais diálogo, uma democracia aberta à participação cidadã e um governo atento, acessível e sensível às diferenças e aos clamores sociais.

A análise histórica denota que a América do Sul é campo fértil para diversas iniciativas de cooperação e integração regional. Os benefícios de décadas de esforços das políticas diplomáticas em mecanismos como ALALC, ALADI, MERCOSUL, Aliança do Pacífico, UNASUL e, mais recentemente, o PROSUL não podem ser olvidados: a região tem um histórico de baixo envolvimento em conflitos internacionais, é livre de armas nucleares e conseguiu superar muitas de suas principais rivalidades geopolíticas. No campo das relações internacionais bilaterais, os países sul-americanos têm logrado desenvolver amplas agendas, especialmente em matéria comercial.

Considerando tratar-se o PROSUL de um projeto bastante recente, não se pode antever tal grau de diferenciação na prática no tocante à UNASUL, tendo em vista 
que as ideias divulgadas sugerem uma natureza de cooperação similar à da organização sul-americana pregressa.

Após o lançamento e formalização de saída da UNASUL, as instâncias diplomáticas dos países do PROSUL, notadamente da diplomacia brasileira, agora devem concentrar esforços em grupos de trabalho para elaborar as bases para a criação da comunidade comum que aperfeiçoe e aprofunde as bases estabelecidas pelo MERCOSUL.

No plano prospectivo, observam-se, entretanto, enormes desafios comuns aos países da região: a defesa inquebrantável da democracia, o desenvolvimento econômico, o combate à criminalidade, o reforço do Estado de Direito, a redução das desigualdades sociais, a proteção ao meio ambiente, dentre outros. A cada novo ciclo político pelo qual a região passa, o equacionamento desses desafios recebe diferentes visões ideológicas e institucionais.

A existência de conflitos é da natureza democrática. Nessa ordem de ideias, um elemento central para o êxito da integração regional sul-americana é a busca na solução para a grave crise atualmente vivenciada na região, especialmente no que concerne ao caso venezuelano. Portanto, faz-se essencial o diálogo diplomático, político e democrático para viabilizar a unidade da América do Sul.

A única saída viável na construção de um genuíno projeto integracionista regional sul-americano se dá pela valorização da política democrática que reúne condições de articular a complexidade e fundar as bases necessárias para o resgate da confiança cidadã, na defesa de sua dignidade e de seus direitos.

\section{Referências bibliográficas}

ARAÚJO, Leandro Rocha de. Associação Latino-Americana de Integração (ALADI). IN MERCADANTE, Araminta de Azevedo. CELLI JUNIOR, Umberto. ARAÚJO, Leonardo Rocha de (coordenadores). Blocos econômicos e integração na América Latina, África e Ásia. Curitiba: Juruá, 2008.

BEIRÃO, André Panno. Há respaldo jurídico e vontade internacional para a integração de defesa na América do Sul? In: MENEZES, Wagner (coordenador). Estudos de Direito Internacional: anais do $8^{\circ}$ - Congresso Brasileiro de Direito Internacional. Curitiba: Juruá, 2010. 
BOBBIO, Norberto. Direita e esquerda: razões e significados de uma distinção política. Tradução: Marco Aurélio Nogueira. $3^{\text {a }}$ - edição. São Paulo: Editora UNESP, 2011.

BORGES, José Souto Maior. Curso de Direito Comunitário. Instituições de direito comunitário comparado: União Européia e Mercosul. São Paulo: Saraiva, 2005.

MÁRQUEZ, Gabriel García. Gabo e a solidão da América Latina. Disponível em: < http://operamundi.uol.com.br/dialogosdosul/gabo-e-a-solidao-da-america-

latina/22042014/>. Acesso em: 28.03.2020.

MESQUITA, Paulo Estivallet de. Novos sinais para a política externa brasileira na América Latina. V Conferência sobre Relações Exteriores: o Brasil e as tendências do cenário internacional. Sérgio Eduardo Moreira Lima e Augusto W. M. Teixeira Júnior (organizadores). - Brasília: FUNAG, 2018.

MOREIRA, Luiz Felipe Viel; QUINTEROS, Marcela Cristina; SILVA, André Luiz Reis da. As relações internacionais da América Latina. Petrópolis, RJ: Vozes, 2010. RIBEIRO, Darcy. O povo brasileiro: a formação e o sentido do Brasil. São Paulo: Companhia das Letras, 2.006.

RICUPERO, Rubens. A diplomacia na construção do Brasil: 1750-2016. $1^{\text {a }}$ - edição. Rio de Janeiro: Versal Editores, 2017.

ROBLES, Gregorio. Los derechos fundamentales y la ética em la sociedad actual. Reimpresión Revisada. Madrid: Editorial Civitas, S.A., 1997.

PAGLIARI, Graciela de Conti. Segurança regional e política externa brasileira: as relações entre Brasil e América do Sul, 1990-2006. Tese de Doutoramento. Universidade de Brasília, Brasília, 2009.

SALOMON, Mónica; PINHEIRO, Letícia. Análise de Política Externa e Política Externa Brasileira: trajetória, desafios e possibilidades de um campo de estudos. Revista brasileira de política internacional, Brasília, v. 56, n. 1, p. 40-59, 2013.

SEN, Amartya. A ideia de justiça. Tradução: Denise Bottmann e Ricardo Doninelli Mendes. São Paulo: Companhia das Letras, 2.011.

SANTOS, Eduardo dos. América do Sul In: MOSCARDO, Jerônimo; CARDIM, Carlos Henrique (organizadoras). O Brasil no mundo que vem aí. Brasília: FUNAG, 2010. 
SIMÕES, Antonio José Ferreira. Integração: sonho e realidade na América do Sul. Brasília: FUNAG, 2011.

SIMÕES, Renata Moraes. A modificação da postura brasileira na UNASUL: da criação à formalização da saída do bloco (2008-2019). Revista Neiba, Cadernos ArgentinaBrasil, UERJ: Rio de Janeiro, 2019. 